\title{
News Literacy:
}

\section{um antídoto contra a desinformação diante da pandemia da Covid-19}

Resumo: A partir de uma reflexão sobre as maneiras como o fenômeno da pandemia da Covid-19 evidencia relações estabelecidas entre política, saúde e desinformação, de um mapeamento de ações que contemplam a news literacy nos cursos de Jornalismo de instituições públicas e privadas e de entrevistas com representantes de organizações da sociedade civil e do mercado profissional, sugerimos que a educação midiática é um antídoto importante para evitar a proliferação de informações falsas.

Palavras-Chave: news literacy; desinformação; pandemia, Covid-19

\section{Alfabetización de noticias: antídoto contra la desinformación frente a la pandemia de Covid-19}

Resumen: A partir de uma reflexión sobre las formas em que el fenómeno de la pandemia de Covid-19 evidencia relaciones estabelecidas entre política, salud y desinformación, um mapeo de acciones que contemplan la alfabetización periodística em cursos de periodismo de instituciones públicas y privadas y entrevistas com representantes de organizaciones de la sociedade civil y del mercado professional, sugerimos que la educación en los médios de comunicación sea um antídoto importante para prevenir la proliferación de información falsa.

Palabras clave: alfabetización de noticias; desinformación; pandemia, Covid-19

\section{News Literacy:an antidote against disinformation in the face of the Covid-19 pandemic}

\footnotetext{
Abstract: From a reflection on the ways in which the Covid-19 pandemic phenomenon highlights relationships established between politics, health and disinformation, a mapping of actions that contemplate news
}

Beatriz Becker
Heitor Machado

Igor Waltz $z^{3}$

Beatriz Santos 4

Andréia Lago ${ }^{5}$

1 Professora Titular do Departamento de Expressão e Linguagens da Escola de Comunicação da UFRJ, docente do Programa de Pós-Graduação em Comunicação e Cultura da UFRJ (PPGCOM-UFRJ), líder do Grupo de Pesquisa Mídia, Jornalismo Audiovisual e Educação (MJAE) e bolsista de Produtividade do CNPq.

2 Doutorando do Programa de Pós-Graduação em Comunicação e Cultura da UFRJ (PPGCOM-

UFRJ), membro do Grupo de Pesquisa Mídia, Jornalismo Audiovisual e Educação (MJAE) e bolsista FAPERJ nota 10.

3 Doutor em Comunicação e Cultura pelo Programa de Pós-Graduação em Comunicação e Cultura da UFRJ (PPGCOM-UFRJ), membro do Grupo de Pesquisa Mídia, Jornalismo Audiovisual e Educação (MJAE) e Professor da Universidade do Estado do Rio de Janeiro.

4 Mestranda do Programa de Pós-Graduação em Comunicação e Cultura da UFRJ (PPGCOM-UFRJ), membro do Grupo de Pesquisa

Mídia, Jornalismo Audiovisual e Educação (MJAE) e bolsista CAPES.

5 Mestranda do Programa de Pós-Graduação em Comunicação e Cultura da UFRJ (PPGCOM-UFRJ), membro do Grupo de Pesquisa

Mídia, Jornalismo Audiovisual e Educação (MJAE) e bolsista CAPES. 


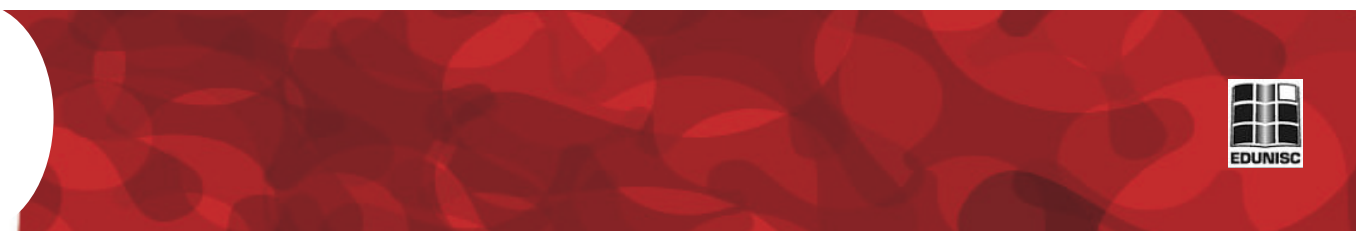

literacy in journalism courses at public and private institutions and interviews with representatives of civil society organizations and of the professional market, we suggest that media education is an important antidote to prevent the proliferation of false information.

Key-words: News literacy; misinformation; pandemic; Covid-19

\section{Introdução}

A pandemia do coronavírus tem causado trágicos impactos sobre vidas humanas e em diferentes setores da sociedade contemporânea em escala planetária, gerando incertezas e inseguranças. Os cidadãos sofrem com a precariedade dos sistemas de saúde e de políticas e serviços públicos protetivos, sobretudo, em países com significativas desigualdades sociais. Para a historiadora Lilia Schwarcz, a pandemia da Covid-19 marca o fim [tardio] do século XX, um período de desenvolvimento tecnológico (BRANDALISE; ROVANI, 2020), cujas premissas de modernização que o impulsionaram são agora desveladas e questionadas. Segundo Boaventura Santos, a atual pandemia deflagra a crise do neoliberalismo sujeito às lógicas do mercado financeiro que, desde 1980, tem legitimado a expressiva concentração de riqueza e impedido que se tome medidas para coibir a catástrofe ecológica, se sobrepondo à vida social e à ética. E a crise financeira ainda é utilizada para explicar cortes em políticas sociais, como na saúde e na educação ou a degradação dos salários. No Brasil, a pandemia, é, sobretudo, uma crise sanitária e humanitária, de acordo com a presidente da Fiocruz, Nísia Trindade Lima (DAHER, 2020). A realidade social do país tem se tornado ainda mais grave em decorrência do negacionismo da doença por parte do governo e das violentas manifestações de seus seguidores contra o isolamento social para a maioria da população, na contramão das orientações da Organização Mundial de Saúde (OMS) e de autoridades sanitárias do país. Estas atitudes muito têm contribuído para o Brasil alcançar um dos mais perversos rankings da atualidade, como o segundo país do mundo com maior número de casos de Covid-19 e também de mortes causadas pela doença que todos os outros 12 países da América do Sul juntos ${ }^{6}$, tornando-se um epicentro do coronavírus, fragilizando a sua inserção no cenário político internacional e na economia global e restringindo a abertura de fronteiras com o país. Segundo o consórcio dos veículos de imprensa, o país confirmou 101.939 mortes e contabilizou 3.062.374 infectados pela Covid-19 no dia 11 de agosto de $2020^{7}$.

O fenômeno da pandemia tem deflagrado uma crise socioeconômica e política, caracterizada por uma disputa de narrativas que envolve a imprensa e a proliferação de fake news ${ }^{8}$.
6 BRASIL É $2^{\circ}$ NO RANKING MUNDIAL EM NOVAS MORTES POR COVID-19, 2020

7 BRASIL REGISTRA MAIS DE 103 MIL MORTES POR COVID-19,

2020

8 As fake news são aqui compreendidas como uma instância do caos informacional da sociedade contemporânea, um mecanismo criado por determinados grupos para enganar cidadãos com o objetivo de obter benefícios políticos e/ou econômicos ou para aprofundar divisões ideológicas na sociedade, por meio da disseminação de desinformação. $\mathrm{O}$ fenômeno das fake news afeta a sociedade contemporânea e, sobretudo, o jornalismo, refletindo uma desconfiança na credibilidade dos relatos jornalísticos ancorados na objetividade dos fatos e um questionamento sobre a existência de uma verdade. Tal fenômeno, porém, não é novo e pode ser comparado, em outra escala, ao boato de antigamente. De fato, a expressão fake news é um oxímoro, devido ao paradoxo que a expressão "notícia falsa" encerra

(BECKER, GOES, 2020). 
Neste cenário, a busca por notícias confiáveis para orientação cresce do mesmo modo que a disseminação de informações falsas nas redes sociais (BITENCOURT et al, 2020). A própria OMS empenha-se para controlar o vírus da desinformação designado de "infodemia" (OPAS, 2020), pois a disseminação de informações falsas coloca em risco a saúde pública. O jornalismo busca reaver a sua credibilidade e os índices de audiência dos programas jornalísticos da Rede Globo, por exemplo, aumentaram $17 \%$, após a principal emissora do país alterar a sua grade de programação e ampliar o espaço do telejornalismo para 11 horas diárias de programação ao vivo (REDE GLOBO, 2020). A visualização de portais informativos também cresceu no ambiente de desordem informativa (WARDLE e DERAKHSHAN, 2017).

No entanto, conforme Amaral (2020), as narrativas jornalísticas de acontecimentos complexos nunca dão conta de sua totalidade, mesmo que riscos possam ser antecipados. Para a pesquisadora, a desigualdade social ainda é abordada de maneira tímida como um problema gerencial e não estrutural, pois falta a inclusão de vozes de especialistas que possam debater os problemas históricos do país (AMARAL, 2020). Contudo, o jornalismo é uma ferramenta de cidadania (SALAVERRÍA, 2020). O bom jornalismo exige mais do que contar ou empacotar histórias, demanda contextualização e explicação dos acontecimentos, análise de suas consequências e riqueza da pluralidade de fontes, o que ressalta a relevância da qualidade de formação dos futuros jornalistas e da leitura crítica de mensagens da mídia. Sugerimos que a educação midiática pode ser um antídoto importante para evitar o colapso não apenas dos sistemas de saúde públicos, mas dos próprios sistemas de informação, e contribuir para uma sociedade mais democrática. Assim, apresentamos neste trabalho uma reflexão sobre as maneiras como o fenômeno da pandemia evidencia relações estabelecidas entre política, saúde e desinformação, um mapeamento de ações que contemplam a news literacy nos cursos de Jornalismo de instituições de ensino superior público e privado e entrevistas com representantes de organizações do mercado profissional e da sociedade civil para mitigar as informações falsas e a cultura do ódio.

\section{Política, Saúde e Desinformação}

Em 31 de dezembro de 2019, a OMS emitiu o primeiro alerta sobre um tipo de pneumonia, ainda de causa desconhecida, identificada na cidade de Wuhan, na China. As primeiras análises indicaram o surgimento de um novo tipo de coronavírus, similar ao da Síndrome Respiratória Aguda Grave (Sars) $)^{9}$. Em poucas semanas, a doença se
9 CRONOLOGIA DA EXPANSÃO DO NOVO CORONAVÍRUS DESCOBERTO NA CHINA, 2020 
espalhou por países de diferentes continentes. O vírus foi nomeado pela OMS de SARS-CoV-2 e a doença causada por ele de Covid-19 (MANZANO, 2020). O Brasil teve o seu primeiro paciente confirmado no final de fevereiro, um homem que retornara da Itália (AQUINO; MONTEIRO, 2020), e em março já haviam centenas de outros casos confirmados ou suspeitos. Ao falar sobre o coronavírus pela primeira vez, durante viagem presidencial aos Estados Unidos, o presidente Jair Bolsonaro (sem partido) afirmou que "o poder destruidor do vírus" estaria sendo superdimensionado (VASCONCELOS, 2020). No dia seguinte, disse que "é mais fantasia a questão do coronavírus, que não é isso tudo que a grande mídia propaga" ${ }^{10}$. Em seguida, a OMS declarou a pandemia do novo coronavírus, mediante o registro de mais de 118 mil casos em 114 países, e 4.291 mortes. O Ministério da Saúde divulgou uma série de recomendações para diminuir a velocidade de transmissão do coronavírus no Brasil, como a suspensão de aulas e de eventos que promoviam aglomerações (MARIZ, 2020). Porém, dois dias depois, sem luvas ou máscara de proteção, o presidente da República apertou a mão e fez fotos com manifestantes reunidos em frente ao Palácio do Planalto, descumpriu recomendação do Ministério da Saúde e voltou a chamar de "histeria" e "extremismo" as medidas para contenção do vírus no país ${ }^{11}$.

Assimcomoemoutrospaíses, prefeitose governadoresestipularam um período de quarentena. O distanciamento social foi adotado em 24 de março na cidade de São Paulo, na mesma semana em que a medida também entrou em vigor no Rio de Janeiro, as duas capitais do país com maior incidência de acometidos pela doença naquele momento ${ }^{12}$. O fechamento do comércio e de atividades econômicas consideradas não-essenciais provocou reações acaloradas de setores alinhados ao governo Bolsonaro. Contrário ao distanciamento social horizontal, o presidente deu declarações e compartilhou vídeo em redes sociais com críticas às restrições adotadas nos estados (PARAGUASSU, 2020), ressaltando os prejuízos à economia e aumento do desemprego decorrentes das medidas contra a pandemia (VARGAS; PORTO, 2020). Na cobertura jornalística diária, ações e afirmações de Bolsonaro eram desmentidas por médicos, pesquisadores e especialistas em infectologia ${ }^{13}$. Em pronunciamento em rede nacional no dia 24 de março, ele ainda acusou a imprensa brasileira de espalhar pânico em torno do coronavírus ${ }^{14}$. A saída do governo de três Ministros de Estado em curto espaço de tempo incrementou a instabilidade política e o tensionamento com os demais poderes de Estado. A relação entre o governo e a imprensa tornou-se ainda mais conflituosa pela atitude violenta de apoiadores do presidente. Eles agrediram os jornalistas que cobriam um ato pró-Bolsonaro no Dia Mundial da Liberdade de Imprensa ${ }^{15}$, no mesmo dia em que o secretário geral da ONU, António
10 BOLSONARO DIZ QUE 'PEQUENA CRISE' DO CORONAVÍRUS É 'MAIS FANTASIA' E NÃO ‘ISSO TUDO’ QUE MÍDIA PROPAGA, 2020

11 BOLSONARO DESCUMPRE MONITORAMENTO POR CORONAVÍRUS, PARTICIPA DE ATO E CUMPRIMENTA APOIADORES NO DF, 2020

12 CORONAVÍRUS: SP E RJ COMEÇAM MAIOR QUARENTENA DO PAÍS, 2020

13 SOCIEDADE BRASILEIRA DE INFECTOLOGIA E OUTRAS ENTIDADES MÉDICAS SE MANIFESTAM SOBRE PRONUNCIAMENTO DE BOLSONARO, 2020

14 BOLSONARO CRITICA IMPRENSA E FECHAMENTO DE ESCOLAS E DIZ QUE CRISE PASSARÁ, 2020

15 PROFISSIONAIS DE IMPRENSA SÃO AGREDIDOS DURANTE MANIFESTAÇÃO ANTIDEMOCRÁTICA COM A PRESENÇA DE BOLSONARO, 2020 
Guterres, defendia o papel crucial de toda a mídia para que a população tome decisões bem informadas durante a pandemia (JOURNALISTS PROVIDE 'ANTIDOTE' TO COVID-19 MISINFORMATION, UN CHIEF SAYS AHEAD OF WORLD PRESS FREEDOM DAY, 2020). Tal ação dos seguidores de Bolsonaro foi repudiada por organizações e instituições democráticas brasileiras. As relações entre Política, Saúde e desinformação tornaram-se cada vez mais entrelaçadas. A chefia do Ministério da Saúde ainda foi trocada duas vezes entre os meses de março e agosto de 2020 e passou a ser comandada por um ministro interino, um general sem experiência prévia na área de saúde (GUILLINO, 2020). Neste cenário, a sociedade brasileira enfrentou informações descoordenadas por parte das autoridades políticas do país (ALVES, 2020).

A avalanche de fake news sobre a origem e disseminação do vírus, sintomas, diagnóstico, tratamentos, estatísticas de contágio e impactos na economia, promoveu a cultura do ódio e afetou a saúde pública no país, levando as pessoas a correrem graves riscos por não terem domínio de critérios de validação de informação (POSETTI e BONTCHEVA, 2020; PINTO, 2019).

\section{A cobertura midiática: pontuando contradições}

A ampla disseminação de informações falsas mobilizou mais de 100 jornalistas de 70 países na Aliança CoronaVirusFacts, uma iniciativa global de checagem de notícias relacionadas à pandemia e disponibilizadas num banco de dados online aberto ao público (POYNTER, 2020). Duas pesquisas divulgadas no mês de março apontaram preocupação com informações disseminadas nas redes sociais sobre o coronavírus e maior confiança do público no jornalismo profissional. Um levantamento da Edelman revelou que $64 \%$ da população em dez países - incluindo o Brasil - vê o trabalho da imprensa como a fonte mais confiável no contexto de pandemia da Covid-19 ${ }^{16}$. O Datafolha apurou que os programas jornalísticos das emissoras de televisão são as fontes com maior índice de confiança (61\%) para informações sobre a doença, seguidos pelos jornais impressos (56\%) (MARQUES, 2020) no país.

As coberturas jornalísticas televisivas constroem a experiência social cotidiana e, ao mesmo tempo, informam e desinformam (BECKER, 2016b). Os telejornais revelam como a pandemia impõe transformações nos modos dominantes de viver, trabalhar e ocupar o tempo, e atiram nos olhos da sociedade o sofrimento dos cidadãos que morrem infectados pela doença sem qualquer atendimento hospitalar. Esses relatos despertam grande atenção e mostram problemas ambientais,
16 A Edelman é uma agência global de comunicação e foi criada para proteger marcas e reputações de empresas e organizações parceiras nos Estados Unidos. Hoje, tal agência é considerada uma das maiores consultoras de relações públicas e marketing no mundo, aferindo em suas pesquisas a credibilidade e a confiabilidade de empresas, governos, organizações não governamentais e da mídia, como a do

Trust Barometer. Tal levantamento abrange mais de 34 mil pessoas em 28 mercados. Disponível em:

$<$ https://www.edelman.com.br/sobrenos>; https://www.edelman.com.br/ estudos/edelman-trust-barometer2020-especial-coronavirus $>$. Acesso em 5 mai. 2020. 
econômicos e sociais. Entretanto, segundo Amaral (2020), a maior parte dos discursos é direcionada à classe média e as instruções de hábitos que devem ser adotados para a prevenção da doença são enunciados para tornar as pessoas responsáveis pelas suas próprias saúdes, sem um efetivo amparo do Estado. Além disso, as reportagens não levam em conta o repertório socioeconômico e cultural e a vivência da maioria da população. As matérias apresentam dados sobre comunidades carentes e não para estes grupos marginalizados. A pesquisadora destaca ainda que as narrativas jornalísticas de acontecimentos complexos minguam após determinado período de tempo, o que não permite um aprofundamento dos problemas estruturais, como a fragilidade do sistema público de saúde, abordados como problemas de gerenciamento. $\mathrm{O}$ jornalismo declaratório e a cobertura realizada em casa e não nas ruas, prejudicada pela falta da devida apuração e ausência de posicionamentos diversos sobre questões relevantes, tampouco contribuem para a ampliação de conhecimentos sobre a realidade social (Idem). De fato, a descrição dos acontecimentos na cobertura do coronavírus pela mídia tem prevalecido sobre a interpretação, o que exige, segundo Pinto (2019), mais transparência e menos objetividade no relato dos fatos, levando em consideração recursos econômicos, sociais e culturais dos receptores.

Nesse sentido, perceber como a informação é produzida, quem produz, quais são as fontes, a credibilidade que merecem e os elementos fornecidos pelo emissor para avaliar a veracidade e a qualidade da informação (PINTO, 2019) torna-se um exercício importante de cidadania. Iniciativas diversas da sociedade civil têm promovido debates e seminários para ampliar a compreensão e a consequência da pandemia. Entretanto, como ressalta Santos (2020), os debates culturais, políticos e ideológicos são opacos e distantes do cotidiano vivido pela grande maioria da população, os cidadãos comuns. As próprias periferias têm implementado modos de atender as comunidades no país, como divulgado pela imprensa em Paraisópolis, São Paulo, e são os movimentos sociais e a Central Única das Favelas (CUFA) que propõem medidas ao poder público para garantir condições protetivas contra o coronavírus à população das favelas (CHIARA, 2020). Neste contexto, tornam-se relevantes projetos específicos em alfabetização midiática para notícias, sobretudo, diante do enorme crescimento das informações falsas (CHAVEZ; MELO, 2019). Assim, buscamos neste trabalho, primeiramente, identificar como os Cursos de Jornalismo do país incorporam práticas pedagógicas, de pesquisa e extensionistas, que buscam contribuir para uma leitura crítica e criativa de notícias e das mensagens da mídia em suportes e linguagens diversos e para um engajamento mais consciente no ambiente midiático convergente, as quais conformam o campo da Media Literacy (BECKER, 2016) ${ }^{17}$.
17 Embora não existe uma única definição para este campo, considerase neste trabalho que a melhor tradução da Media Literacy é a expressão Mídia e Educação, pois congrega a leitura crítica de mensagens da mídia em processos de aprendizagem formais e informais, práticas pedagógicas inovadoras em contextos sociais e culturais diversos, considerando o interesse e o repertório dos estudantes, bem como a inclusão digital, por meio do desenvolvimento de pesquisas acadêmicas e políticas públicas democráticas (BECKER, 2016a). 


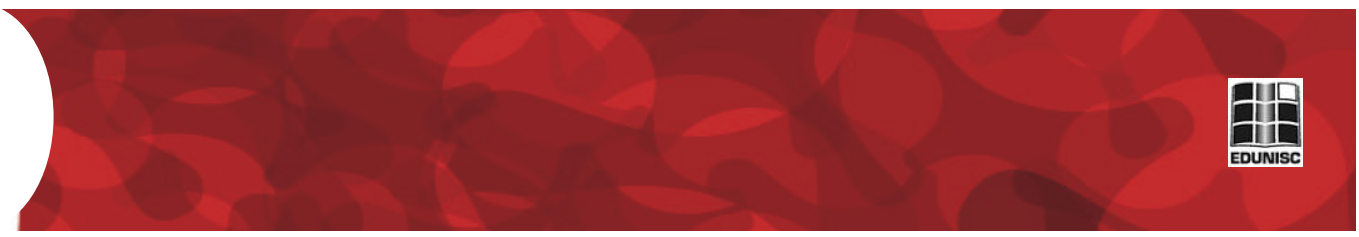

4 Um mapeamento da media literacy nos cursos de jornalismo

18 Disponível em: https://emec. mec.gov.br/. Acesso em: 20/04/2020

Para mapear iniciativas na academia capazes de colaborar para leitura crítica, produção de conteúdos midiáticos mais diversos e compreensão do processo de produção, circulação e consumo de notícias, iniciamos nossa busca no portal do Ministério da Educação $\left(\mathrm{e}-\mathrm{mec}^{18}\right)$, focalizando os cursos de Graduação em jornalismo. O resultado da pesquisa sinalizou 524 cursos no país, entretanto, observamos que os dados disponibilizados de grande parte desses cursos nesta plataforma são repetidos. Excluímos aqueles que foram citados mais de uma vez e chegamos a um total de 331 cursos. Porém, verificamos ainda que em 75 universidades deste conjunto não existe a oferta de Cursos de Jornalismo, o que exigiu a retirada destas instituições de nossa amostra, e chegamos a um número final de 256 cursos de jornalismo distribuídos nas cinco regiões no país: Sudeste (115), Nordeste (54), Sul (47), Centro-Oeste (21) e Norte (19).

Com o intuito de observar o espaço aberto ou não para disciplinas e atividades de pesquisa e extensão que estabelecem relações entre Comunicação e Educação, buscamos explorar outras fontes de pesquisa para refinar os resultados de nosso mapeamento, matrizes curriculares, ementários, projetos pedagógicos dos cursos, registros de grupos de pesquisa e projetos de extensão de distintas instituições de ensino. Nesse percurso, verificamos que apenas 56 cursos $(21,9 \%)$ privilegiam esse campo de conhecimento e que a presença de disciplinas e atividades de extensão e pesquisa que estabelecem relações entre Comunicação e Educação é distribuída de maneira desigual nas regiões do país, 24 na região Sudeste (42,9\%), 11 na região Nordeste $(19,6 \%), 10$ na região Sul $(17,9 \%), 6$ na região Centro-Oeste $(10,7 \%)$ e 5 na região Norte $(8,9 \%)$.

A maior parte destas ações está concentrada nas atividades de ensino e corresponde às disciplinas que integram as matrizes curriculares $(69,6 \%)$, seguida de iniciativas de Grupos de Pesquisa $(20,3 \%)$ e de atividades extensionistas (10,1\%). Identificamos um total de 69 iniciativas, número maior que o total de cursos identificados com a presença de disciplinas e atividades de pesquisa e extensão que abordam relações entre Comunicação e Educação, pois algumas universidades apresentam propostas que articulam essas atividades de maneiras diversas, tanto nas matrizes curriculares de seus cursos de jornalismo quanto em grupos de pesquisa e projetos de extensão.

A partir deste mapeamento foi possível ainda observar que as ações que estabelecem relações entre Comunicação e Educação e se debruçam sobre a leitura crítica e a produção de conteúdos jornalísticos nos cursos identificados são tratadas por nomenclaturas distintas. A 


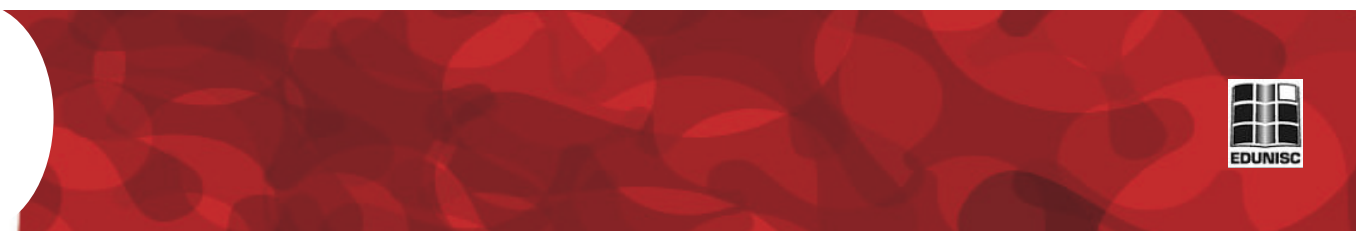

sistematização dos dados do mapeamento realizado demonstra que o termo "Educomunicação" é o mais utilizado em 18,3\% das ações que estabelecem diálogos entre as áreas da Comunicação e da Educação, provavelmente, por reunir o trabalho de pesquisadores renomados, um número significativo de produção científica no país e possuir uma graduação específica na Universidade de São Paulo. A expressão "Comunicação e Educação" evidencia a interdisciplinaridade entre esses saberes e este termo é usado em 12,7\% destas iniciativas, do mesmo modo que "Leitura Crítica da Mídia", também referida como "Leitura crítica da Comunicação" ou "Análise Crítica da Mídia" em algumas instituições. "Mídia e Educação" é o termo adotado em quase $10 \%$ das instituições. "Educação para a mídia", "Comunicação e Cidadania" e outros termos utilizados que traduzem a reunião das áreas de Comunicação e Educação nessas atividades são usados com menor incidência. Contudo, este mapeamento permitiu identificar que estas ações ainda não são privilegiadas em quase a metade dos Cursos de Jornalismo do país. No entanto, observa-se tanto na academia quanto por parte de organizações civis e do mercado um interesse em expandir estas práticas, incrementando a leitura crítica de notícias no ambiente de desordem informativa e no atual contexto político e social do país.

\section{Iniciativas de combate às fake news: vozes do campo da mídia}

O termo News Literacy não tem uma única definição nos estudos acadêmicos (MAKSL, ASHLEY e CRAFT, 2015). Para o Reuters Institute, a news literacy consiste na "habilidade de analisar criticamente notícias e informações que as pessoas recebem por diferentes fontes" (apud CHAVES e MELO, 2019, p.64). Mas, essa competência não deixa de estar inserida nas premissas da Media Literacy, pois o letramento midiático deve estimular o desenvolvimento de habilidades analíticas e capacidade crítica e não ater-se apenas às competências tecnológicas nos usos das ferramentas (HOBBS, 2014). Nesse sentido, Cooke (2018) argumenta que a educação midiática deve abranger diversos conjuntos de literacias, como o audiovisual, o digital e o noticioso. Esse último pode ser compreendido como uma subárea da media literacy, aplicada ao ciclo de produção da notícia, de forma a habilitar os cidadãos a selecionar, compreender e avaliar as notícias, promovendo a consciência democrática cívica (DVORKIN, 2018; MIHAILIDIS, 2012).

Para Mihailidis (2016), o ensino, a pesquisa e a prática da news literacy deve ter em consideração um diálogo próximo com o campo profissional do jornalismo, assim como ter em vista os modos como 


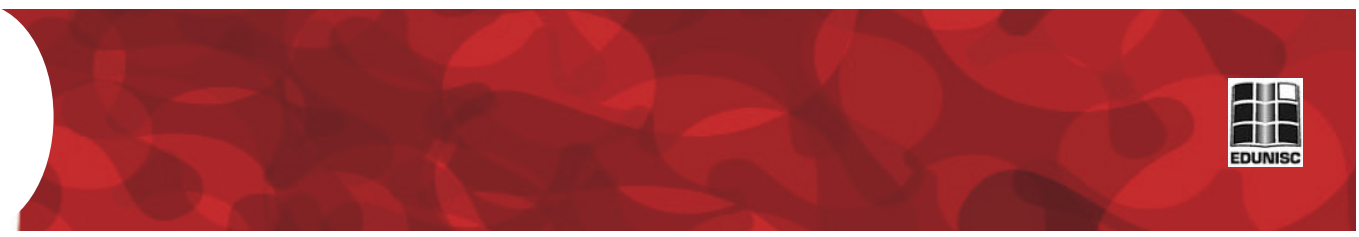

novas tecnologias e novas práticas estão redefinindo as notícias na cultura digital. De tal modo, uma compreensão abrangente do cenário contemporâneo da news literacy no Brasil, além de abordagens propostas pelas instituições acadêmicas, demanda também uma investigação das iniciativas geradas por empresas, organizações e profissionais do campo da mídia.

Assim, buscamos, em um segundo momento de nossa investigação, analisar também os modos como o campo da mídia compreende e aplica a news literacy, por meio de entrevistas realizadas por email e/ou gravadas por telefone e posteriormente transcritas, com representantes das Redes Cordiais, LupaEducação e EducaMídia, identificando seus objetivos, motivações, desafios e métodos de trabalho. O projeto Redes Cordiais (https://www. redescordiais.com.br/), criado pelas jornalistas Clara Becker e Alana Rizzo, promove treinamentos com influenciadores digitais baseados em três áreas: educação digital para redes sociais (social media literacy), comunicação não-violenta e combate à desinformação e às fake news. Já o LupaEducação (https://piaui.folha.uol.com.br/lupa/2017/03/28/lupa-educacao/) é o braço educacional da Agência Lupa, startup jornalística especializada em fact checking, que realiza palestras e cursos para jornalistas, estudantes e cidadãos em geral. Inicialmente direcionado ao ensino de técnicas e ferramentas de verificação de informações, o programa ampliou seu escopo de educação midiática, a fim de promover leituras críticas e combater as notícias falsas. O EducaMídia (https://educamidia.org.br/quemsomos), por sua vez, é um programa de capacitação de professores dos ensinos fundamental e médio em educação midiática dos jovens, criado pela entidade sem fins lucrativos Instituto Palavra Aberta, que se fundamenta na interpretação crítica, produção de conteúdos e participação responsável na sociedade. No Quadro 1 abaixo, apresentamos um breve perfil dos entrevistados e das organizações e sintetizamos as respostas referentes às principais questões abordadas nas oito perguntas feitas aos entrevistados, previamente elaboradas. 


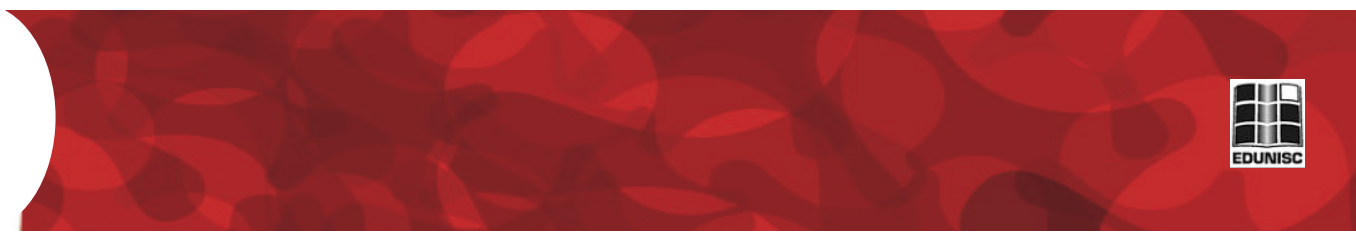

Quadro 1: práticas de News Literacy na mídia

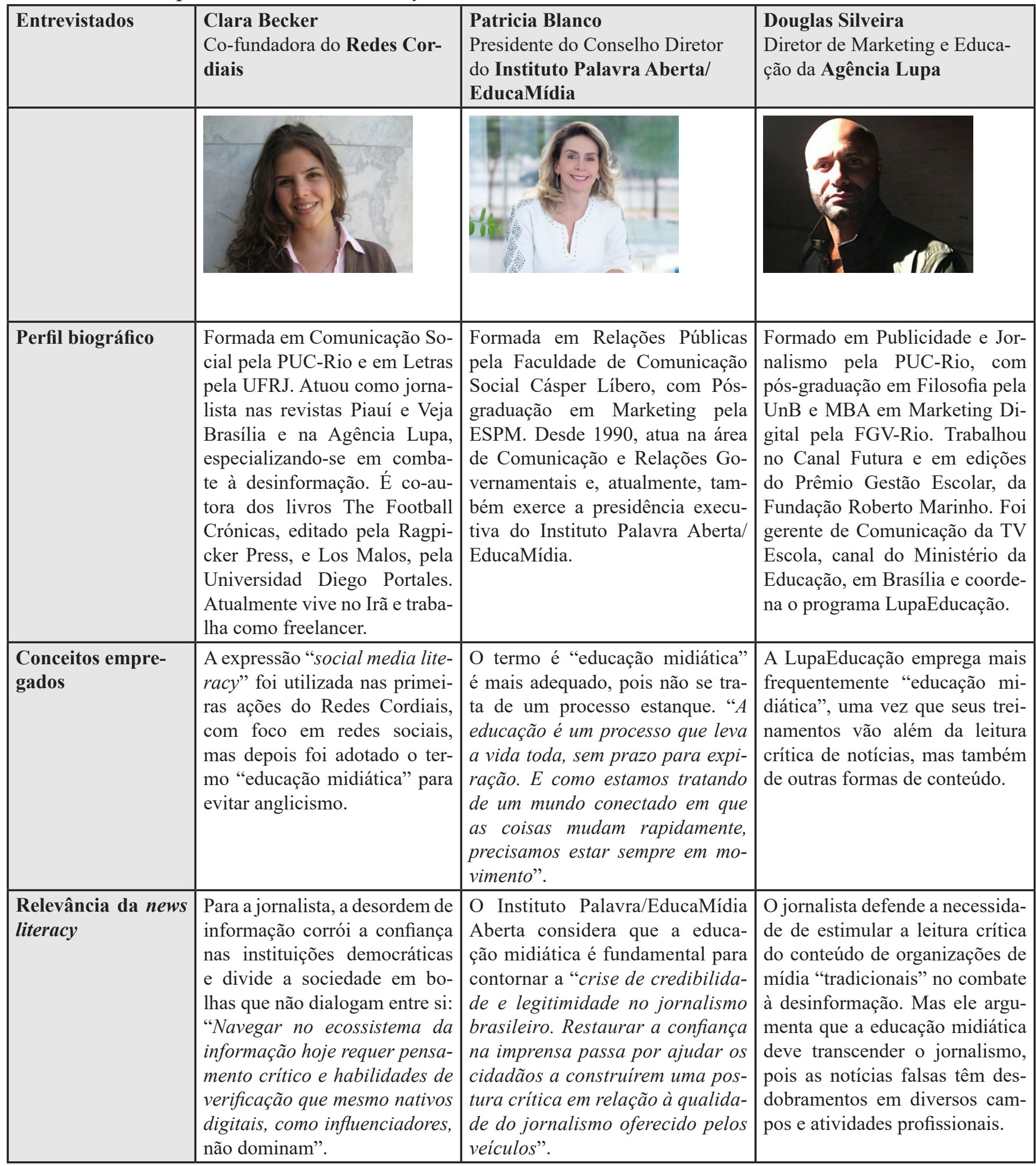




\begin{tabular}{|c|c|c|c|}
\hline Modelos de atuação & $\begin{array}{l}\text { O Redes Cordiais conta com } \\
\text { recursos de fundações do ter- } \\
\text { ceiro setor, de projetos com a } \\
\text { iniciativa privada e de doações } \\
\text { de pessoas físicas. O trabalho } \\
\text { desenvolvido tem foco no trei- } \\
\text { namento de comunicadores di- } \\
\text { gitais no combate ao discurso e } \\
\text { à cultura de ódio e às notícias } \\
\text { falsas, mediante parcerias com } \\
\text { outras entidades e organiza- } \\
\text { ções, como Agência Lupa, e } \\
\text { oficinas de comunicação não- } \\
\text { violenta para influenciadores. }\end{array}$ & $\begin{array}{l}\text { Vinculado a uma entidade sem } \\
\text { fins lucrativos, o Instituo Palavra } \\
\text { Aberta/ EducaMídia também con- } \\
\text { ta com parcerias para sua atuação. } \\
\text { Além dos recursos do próprio Ins- } \\
\text { tituto Palavra Aberta, mantido pela } \\
\text { contribuição dos seus associados, } \\
\text { o projeto é contemplado pelo } \\
\text { Google.org, braço filantrópico do } \\
\text { Google. A entidade oferece uma } \\
\text { plataforma com materiais pedagó- } \\
\text { gicos disponíveis para professores } \\
\text { e alunos. }\end{array}$ & $\begin{array}{l}\text { O LupaEducação está inserido } \\
\text { no modelo de negócios da Agên- } \\
\text { cia Lupa. Suas ações incluem } \\
\text { palestras e cursos presenciais e } \\
\text { online no Brasil e no exterior, } \\
\text { treinamentos corporativos con- } \\
\text { tratados por empresas, oficinas } \\
\text { em instituições de ensino públi- } \\
\text { cas e outros projetos, mantidos } \\
\text { por meio de parcerias diversas } \\
\text { (Google, Facebook, Canal Futu- } \\
\text { ra, Instituto Tecnologia \& Equi- } \\
\text { dade-IT\&E e APPCívico). }\end{array}$ \\
\hline Motivações & $\begin{array}{l}\text { Mitigar a desinformação e } \\
\text { qualificar diálogos nas redes } \\
\text { sociais, por meio da educação } \\
\text { midiática. }\end{array}$ & $\begin{array}{l}\text { Formar ética e criticamente cida- } \\
\text { dãos e cidadãs para o mundo co- } \\
\text { nectado, contribuindo para que to- } \\
\text { mem as melhores decisões na hora } \\
\text { de se informar e consumir conteú- } \\
\text { dos online e off-line. }\end{array}$ & $\begin{array}{l}\text { Repensar as plataformas digi- } \\
\text { tais, que não podem mais ser } \\
\text { compreendidas como uma "se- } \\
\text { gunda tela", pois são o principal } \\
\text { meio de informação de uma sig- } \\
\text { nificativa parcela da sociedade. }\end{array}$ \\
\hline Desafios & $\begin{array}{l}\text { Sensibilizar e atrair influencia- } \\
\text { dores para o seu treinamento. }\end{array}$ & $\begin{array}{l}\text { Combater as disparidades edu- } \\
\text { cacionais no Brasil e a crescente } \\
\text { deslegitimação do trabalho da im- } \\
\text { prensa, ressaltando a importância } \\
\text { da qualidade da informação. }\end{array}$ & $\begin{array}{l}\text { Educar pessoas idosas em rela- } \\
\text { ção para as mídias e inserir no } \\
\text { currículo dos cursos de jornalis- } \\
\text { mo atividades de fact-checking e } \\
\text { leitura crítica de notícias. }\end{array}$ \\
\hline $\begin{array}{l}\text { O letramento mi- } \\
\text { diático e o ensino de } \\
\text { jornalismo }\end{array}$ & $\begin{array}{l}\text { A jornalista considera essencial } \\
\text { uma disciplina de letramento } \\
\text { midiático nas faculdades de } \\
\text { jornalismo, bem como "uma } \\
\text { educação para o consumo da } \\
\text { informação nas redes sociais". }\end{array}$ & $\begin{array}{l}\text { O Instituto Palavra Aberta/ Edu- } \\
\text { ca Mídia ressalta que a educação } \\
\text { midiática e a compreensão do pro- } \\
\text { cesso de produção da notícia são } \\
\text { relevantes para interagir com a mí- } \\
\text { dia com responsabilidade e senso } \\
\text { crítico. }\end{array}$ & $\begin{array}{l}\text { Para o LupaEducação há } \\
\text { necessidade de educar futuros } \\
\text { comunicadores, incorporando } \\
\text { tecnologias e inovação e os alu- } \\
\text { nos têm esse interesse. Porém, } \\
\text { ele observa resistências de pro- } \\
\text { fessores } e \text { reitores. }\end{array}$ \\
\hline $\begin{array}{l}\text { O jornalismo no } \\
\text { contexto da Co- } \\
\text { vid-19 }\end{array}$ & $\begin{array}{l}\text { Para a representante das Redes } \\
\text { Cordiais, "abriu-se uma janela } \\
\text { de oportunidade para a reva- } \\
\text { lorização do jornalismo (...). } \\
\text { Evidente que a desinformação } \\
\text { é uma ameaça à saúde pública. } \\
\text { Quem valoriza a própria saúde } \\
\text { e a saúde da sociedade precisa } \\
\text { entender a responsabilidade } \\
\text { de aprender sobre conteúdos } \\
\text { enganosos e combatê-los". }\end{array}$ & $\begin{array}{l}\text { Segundo o Educa Mídia, "[O pa- } \\
\text { pel do jornalismo é] informar com } \\
\text { credibilidade. Estamos em meio à } \\
\text { maior crise de saúde pública da } \\
\text { nossa era, o que angustia e de- } \\
\text { sespera as pessoas. Informação } \\
\text { de qualidade é uma espécie de } \\
\text { antídoto para esse clima caótico e } \\
\text { uma vacina contra a desinforma- } \\
\text { ção". }\end{array}$ & $\begin{array}{l}\text { O jornalista responsável pelo } \\
\text { Lupa-Educação ressalta que "se } \\
\text { de um lado, vemos profissionais } \\
\text { de saúde lutando contra a doen- } \\
\text { ça, expondo suas vidas para } \\
\text { salvar vidas, por outro lado, te- } \\
\text { mos os jornalistas, seja em suas } \\
\text { casas ou nas redações, lutando } \\
\text { contra outra epidemia, a da de- } \\
\text { sinformação". }\end{array}$ \\
\hline
\end{tabular}

Fonte: autoria própria

Os representantes das Redes Cordiais, do Instituto Palavra (EducaMídia) e da Agência Lupa acreditam que a tradução mais adequada da expressão news literacy é educação midiática. Seus depoimentos revelam a crescente relevância dessa prática, ainda que utilizando uma variabilidade de modelos de atuação, métodos de trabalho e de captação de recursos e parcerias. As principais 
motivações do trabalho que realizam são promover práticas nãoviolentas de comunicação e combater a desordem informativa. Eles reconhecem a importância de pensar a educação midiática também na formação dos futuros profissionais e são unânimes em apontar que o jornalismo é revalorizado no atual cenário político, afligido por posições polarizadas e pela desinformação.

\section{Considerações Finais}

Diante da pandemia da Covid-19 as informações falsas são tanto um problema político quanto de saúde pública. As práticas jornalistas devem contribuir para a formulação de políticas públicas capazes de promover mudanças sociais, condições de vida digna à população e respeito aos direitos humanos e às diferenças. Segundo Pereira (2020), a checagem da origem e busca de fontes primárias das informações, a leitura crítica dos textos da mídia e o uso de tecnologias para transformação das comunidades é relevante para desconstruir preconceitos e evitar a desinformação ${ }^{19}$. O ensino do jornalismo também precisa estar comprometido com a produção de informações bem apuradas, confiáveis e transparentes. $\mathrm{Na}$ formação dos futuros jornalistas um repertório conformado por conteúdos disciplinares sobre ética, história, questões sociais e literatura, que permita interpretar a sociedade contemporânea, é tão importante quanto o conhecimento sobre estruturas das empresas de comunicação, processos econômicos que funcionam no mundo, direito à informação e destrezas profissionais necessárias para a produção de conteúdo jornalístico (SALAVERRÍA, 2020). Para o pesquisador Ramon Salaverría, a alfabetização midiática rende resultados bem melhores do que ações judiciais para combater a disseminação de informações falsas, pois permite apreender elementos que podem nos alertar sobre a manipulação de uma informação ${ }^{20}$.

Contudo, as práticas de news literacy não estão restritas aos espaços formais de educação e ao campo da mídia. Em um cotidiano social cada vez mais mediado pelas múltiplas telas nas quais circulam uma abundância de informações distribuída de maneira acelerada, pessoas de todas as idades têm apreendido o que se passa no país e no mundo pelas redes sociais e dispositivos móveis, sem verificar a credibilidade das fontes e estabelecendo uma relação emocional com as notícias. Assim, consideramos que a news literacy ou a educação midiática pode ser um antídoto importante para evitar o colapso não apenas dos sistemas de saúde, mas do próprio sistema de informação e, em acordo com o posicionamento do secretário geral da ONU,
19 Cf: https://www.abpeducom.org. br/educomunicacao-contribui-para-combate-ao-novo-coronavirus/. Acesso em 11 mai, 2020.

20 Cf: https://www.academia. edu/43016142/Ram\%C3\%B3n Salaverr\%C3\%ADa_El_problema_ahora_no_es_encontrar_las_noticias_sino_encontrar_la_verdad?email_work_card=view-paper. Acesso em 12 mai, 2020. 
António Guterres, também contra à infodemia. Afinal, como destaca Santos (2020), o que o fenômeno do coronavírus nos permite ver e o como isso for interpretado e avaliado determinarão o futuro da civilização em que vivemos.

\section{REFERÊNCIAS}

ALVES, Chico. Bolsonaro é obstáculo para ministros da Saúde na luta contra a pandemia. UOL, Coluna Chico Alves, 2020. Disponível em: $\quad<$ https://noticias.uol.com.br/colunas/chico-alves/2020/05/14/ bolsonaro-e-obstaculo-para-ministros-da-saude-na-luta-contra-apandemia.htm>. Acesso em: 15 mai. 2020.

AMARAL, Márcia. Entrevista Objethos, Observatório da Ética Jornalística. Disponível em: < https://objethos.wordpress. com/2020/04/08/marcia-amaral-regras-absolutas-nao-servem-nacobertura-de-acontecimentos-extremos/>. Acesso em 12 mai, 2020.

AQUINO, Vanessa; MONTEIRO, Natália. Brasil confirma primeiro caso da doença. Ministério da Saúde - Agência Saúde, 2020. Disponível em: <https://www.google.com / search? $\mathrm{q}=$ primeiro $+\mathrm{cas} o+\mathrm{de}+$ coronavirus $\& \mathrm{oq}=$ primeiro + caso + de + coronavirus \&aqs $=$ chrome..69i57j017.2941j0j4\&sourceid $=$ chrome\&ie $=\mathrm{UTF}-8>$. Acesso 13 abr. 2020.

BECKER, B. Mídia, Telejornalismo e Educação. Matrizes: Revista do Programa de Pós-Graduação em Ciências da Comunicação da Universidade de São Paulo, São Paulo: ECA/USP, v. 10, n. 1, $2016 a$. DOI: $\quad$ https://doi.org/10.11606/issn.1982-8160.v10i1p149-164. Acesso em: 16 de abr. de 2020.

. Televisão e Telejornalismo: Transições. São Paulo:

Estação das Letras e Cores, 2016 b.

BECKER, Beatriz. GOES, Francisco. Fake News: uma definição possível entre a reflexão crítica e a experiência jornalística. Âncora, Revista Latino-americana de jornalismo, Programa de PósGraduação em Jornalismo, UFPB, Vol.7, N.1, 2020, p.1-20. No prelo.

BITENCOURT, Rafael; MURAKAWA, Fábio; CAMAROTTO, Mirillo. 'Fake news crescem mais do que número de casos', diz Mandetta. Valor, 2020. Disponível em: <https://valor.globo.com/ 
brasil/noticia/2020/04/07/fake-news-crescem-mais-do-que-numerode-casos-diz-mandetta.ghtml>. Acesso em: 22 abr. 2020.

BOLSONARO DIZ QUE 'PEQUENA CRISE' DO CORONAVÍRUS É 'MAIS FANTASIA' E NÃO 'ISSO TUDO' QUE MÍDIA PROPAGA. G1, 2020. Disponível em: <https://g1.globo.com/politica/ noticia/2020/03/10/bolsonaro-diz-que-questao-do-coronavirus-emuito-mais-fantasia.ghtml>. Acesso em 5 mai. 2020.

BOLSONARO DESCUMPRE MONITORAMENTO POR CORONAVÍRUS, PARTICIPA DE ATO E CUMPRIMENTA APOIADORES NO DF. G1, 2020. Disponível em: <https://g1.globo. com/politica/noticia/2020/03/15/mesmo-com-recomendacao-demonitoramento-por-coronavirus-bolsonaro-participa-de-carro-de-atoem-brasilia.ghtml>. Acesso em: 5 mai. 2020.

BOLSONARO CRITICA IMPRENSA E FECHAMENTO DE ESCOLAS E DIZ QUE CRISE PASSARÁ. UOL, 2020. Disponível em: $<$ https://noticias.uol.com.br/politica/ultimas-noticias/2020/03/24/ covid-19-bolsonaro-culpa-imprensa-por-panico-e-volta-a-falargripezinha.htm?cmpid=copiaecola $>$. Acesso em: 6 mai. 2020.

BRANDALISE, Camila; ROVANI, Andressa. 100 dias que mudaram o mundo. Universa, UOL, 2020. Disponível em: <https://www.uol. com.br/universa/reportagens-especiais/coronavirus-100-dias-quemudaram-o-mundo/\#cover>. Acesso em: 11 mai. 2020.

BRASIL É $2^{\circ}$ NO RANKING MUNDIAL EM NOVAS MORTES POR COVID-19, DIZ OMS. UOL, 2020. Disponível em: <https:// noticias.uol.com.br/ultimas-noticias/2020/08/08/coronavirusbalanco-da-oms-registra-716075-mortes-e-19187943-casos-nomundo.htm?cmpid=copiaecola $>$. Acesso em: 11 ago. 2020.

BRASIL REGISTRA MAIS DE 103 MIL MORTES POR COVID-19; FORAM 56.081 NOVOS CASOS EM 24 HORAS. G1 - Globo, 2020. Disponível em: <https://g1.globo.com/bemestar/coronavirus/ noticia/2020/08/11/casos-e-mortes-por-coronavirus-no-brasil-em11-de-agosto-segundo-consorcio-dos-veiculos-de-imprensa.ghtml>. Acesso em: 11 ago. 2020.

CHAVES, M.; MELO, L. Educação midiática para notícias: histórico e mapeamento de iniciativas para combater a desinformação por meio da educação. Revista Mídia e Cotidiano, v. 13, n. 3, 2019, p. 62-82. Disponível em: <http://periodicos.uff.br/midiaecotidiano/ 
article/view/38091>. Acesso em: 27 abr. 2020.

CHIARA, Márcia de. Paraisópolis cria rede de solidariedade para conter danos do Coronavírus. Estadão, 2020. Disponível em: $<$ https://saude.estadao.com.br/noticias/geral,paraisopolis-cria-redede-solidariedade-para-conter-danos-do-coronavirus,70003270413>. Acesso em: 25 set. 2020.

COOKE, Nicole A. Fake news and alternative facts: Information literacy in a post-truth era. Chicago: American Library Association, 2018.

CORONAVÍRUS: SP E RJ COMEÇAM MAIOR QUARENTENA DO PAÍS. Exame, 2020. Disponível em: <https://exame.com/ brasil/sp-e-rj-comecam-maior-quarentena-do-pais/\#: :text=Por $\% 20$ Reda $\%$ C3\%A7\%C3\%A30\%20EXAME\&text $=$ S $\%$ C3\%A3o\%20 Paulo\%20e\%20Rio\%20de,restri\%C3\%A7\%C3\%A30\%20\%C3\%A0\%20circula $\% \mathrm{C} 3 \% \mathrm{~A} 7 \% \mathrm{C} 3 \% \mathrm{~A} 3 \mathrm{o} \% 20 \mathrm{de} \% 20$ pessoas.>. Acesso em: 13 abr. 2020.

CRONOLOGIA DA EXPANSÃO DO NOVO CORONAVÍRUS DESCOBERTO NA CHINA. G1, 2020. Disponível em: <https:// g1.globo.com/ciencia-e-saude/noticia/2020/01/22/cronologia-daexpansao-do-novo-coronavirus-descoberto-na-china.ghtml>. Acesso 13 abr. 2020.

DAHER, Valquíria. A Fiocruz diante da Covid-19. Ciência Hoje, 2020. Disponível em: <http://cienciahoje.org.br/artigo/a-fiocruzdiante-da-covid-19/>. Acesso em: 13 mai. 2020.

DVORKIN, Jeffrey. Critical news literacy. New York: Routledge, 2018.

EDELMAN. Trust Barometer 2020. Relatório especial: Confiança e o Coronavírus. Resultados brasileiros, 2020. Disponível em: $<$ https://www.edelman.com.br/sites/g/files/aatuss291/files/2020-03/ Edelman\%20Trust\%20Barometer\%202020_Coronavirus_Brasil\%20 com\%20Global.pdf>. Acesso em 29 abr. 2020.

EDUCAMÍDIA. EducaMídia, 2020. Disponível em: <https:// educamidia.org.br/quem-somos>. Acesso em: 25 set. 2020.

GUILLINO, Daniel. Governo oficializa general Pazuello como ministro interino da Saúde. O Globo, 2020. Disponível em: $<$ https:// 
oglobo.globo.com/sociedade/governo-oficializa-general-pazuellocomo-ministro-interino-da-saude-1-24459898>. Acesso em: 25 set. 2020.

LUPA EDUCAÇÃO. Piauí, UOL, 2020. Disponível em: <https:// piaui.folha.uol.com.br/lupa/2017/03/28/lupa-educacao $>$. Acesso em: 25 set. 2020 .

MARQUES, José. TVs e jornais lideram índice de confiança em informações sobre coronavírus, diz Datafolha, Folha de S. Paulo, 2020. Disponível em: <https://www1.folha.uol.com.br/poder/2020/03/ tvs-e-jornais-lideram-indice-de-confianca-em-informacoes-sobrecoronavirus-diz-datafolha.shtml>. Acesso em: 29 abr. 2020.

HOBBS, R. Digital and Media Literacy: Connecting Culture and Classroom. Thousand Oaks, CA: Corwin, 2011.

Reflection on News Literacy. Renee Hobbs at the Media Education Lab, 2014. Disponível em: https://mediaedlab. com/2014/09/08/reflection-on-news-literacy/>. Acesso em: 27 abr. 2020 .

JOURNALISTS PROVIDE 'ANTIDOTE' TO COVID-19 MISINFORMATION, UN CHIEF SAYS AHEAD OF WORLD PRESS FREEDOM DAY. UN News, 2020. Disponível em: <https:// news.un.org/en/story/2020/05/1063012>. Acesso em 6 mai. 2020.

MAKSL, A; CRAFT S.;ASHLEY, S. The Usefulness of a News Media Literacy Measure in Evaluating a News Literacy Curriculum. Journalism@Mass Communication Educator (aejmc), 2016.

MANZANO, Fabio. Doença provocada pelo novo coronavírus é batizada de Covid-19pela OMS. G1 Ciência e Saúde, 2020. Disponível em: $<$ https://g1.globo.com/ciencia-e-saude/noticia/2020/02/11/omsda-nome-a-doenca-provocada-pelo-novo-coronavirus-covid-19. ghtml>. Acesso 13 abr. 2020.

MARIZ, Renata. Ministério da Saúde recomenda adiar eventos com aglomeração de pessoas. O Globo, 2020. Disponível em: <https:// oglobo.globo.com/sociedade/ministerio-da-saude-recomenda-adiareventos-com-aglomeracao-de-pessoas-1-24303045>. Acesso em 5 mai. 2020. 
MIHAILIDIS, Paul. Exploring news literacy: Preparing future journalists - and citizens - for engagement in global digital culture. Journalism Education. Association for Journalism Education, v.5, n.1, 2016. Disponível em <https://www.academia.edu/27138511/ Exploring_News_Literacy_Preparing_future_journalists_and_ citizens_for_engagement_in_global_digital_culture $>$. Acesso em 7 jan. 2020.

News Literacy: Global perspectives for the newsroom and the classroom. New York: Peter Lang, 2012.

OPAS. ENTENDA A INFODEMIA E A DESINFORMAÇÃO NA LUTA CONTRAA COVID-19. PAHO, 2020. Disponível em: $<$ https:// iris.paho.org/bitstream/handle/10665.2/52054/Factsheet-Infodemic por.pdf? sequence $=14>$. Acesso em: 13 mai. 2020 .

PARAGUASSU, Lisandra. Bolsonaro divulga vídeo de apoiadora com crítica a governadores. Economia UOL, 2020. Disponível em: $<$ https://economia.uol.com.br/noticias/reuters/2020/04/02/bolsonarodivulga-video-de-apoiadora-com-critica-a-governadores-e-diz-queela-fala-por-milhoes.htm>. Acesso em 5 mai. 2020.

PINTO, M. Educação para a Comunicação Social: experiências educativas com o jornalismo em Portugal. [Entrevista concedida a] REHDER, M.; SALDANHA, F. Comunicação \& Educação, 24(1), 2019, 95-107. Disponível em: <https://doi.org/10.11606/issn.23169125.v24i1p95-107> Acesso em: 20 abr. 2020.

POSETTI, Julie; BONTCHEVA, Kalina. Disinfodemic: Deciphering Covid-19 Desinformation. United Nations Educational, Scientific and Cultural Organization, 2020. Disponível em: $<$ https://en.unesco. org/sites/default/files/disinfodemic_deciphering_covid19_ disinformation.pdf $>$. Acesso em: 10 mai. 2020.

POYNTER. Covid-19: Poynter Resources. Poynter Institute, 2020. Disponível em: $<$ https://www.poynter.org/coronavirusfactsalliance/>. Acesso em: 6 mai. 2020.

PROFISSIONAIS DE IMPRENSA SÃO AGREDIDOS DURANTE MANIFESTAÇÃO ANTIDEMOCRÁTICA COM A PRESENÇA DE BOLSONARO. G1 Política, 2020. Disponível em: <https://g1.globo. com/politica/noticia/2020/05/03/profissionais-de-imprensa-saoagredidos-durante-manifestacao-antidemocratica-com-a-presencade-bolsonaro.ghtml>. Acesso em: 25 set. 2020. 


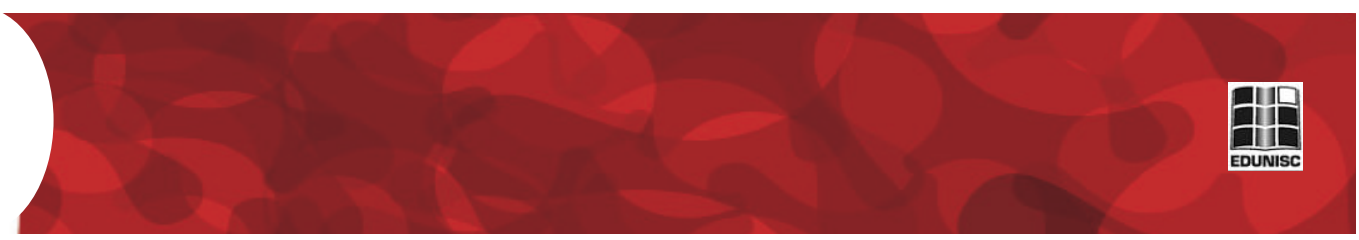

REDE CORDIAIS. Rede Cordiais, 2020. Disponível em: <https:// www.redescordiais.com.br/>. Acesso em: 25 set. 2020.

REDE GLOBO. A Jornada de Consumo de Conteúdo do Brasileiro. Negócios Globo, 2020. Disponível em: <https:// negocios8.redeglobo.com.br/Storage $\% 20 \% 20$ COMUNICACAO $\% 20$ MER C A D O L O G I C A / A \% 20 J O R N A D A \% 20 DE \% 20 CONSUMO $\% 20 \mathrm{DE} \% 20 \mathrm{CONTE} \% \mathrm{C} 3 \% 9 \mathrm{ADO} \% 20 \mathrm{DO} \% 20$ BRASILEIRO_2.pdf $>$. Acesso em: 14 abr. 2020.

SANTOS, Boaventura de Sousa. A Cruel Pedagogia do Vírus. São Paulo: Boitempo, 2020.

SALAVERRÍA, Ramon. O jornalismo é tautológico! Pois é um fazer que contém em si todos os significados. Entrevista à Carlos Costa. Revista Brasileira de Ciências da Comunicação (RBCC), v. 43, n.1, 2020. Disponível em: https://doi.org/10.1590/1809-58442020110. Acesso em: 12 mai 2020.

\section{SOCIEDADE BRASILEIRA DE INFECTOLOGIA E OUTRAS} ENTIDADES MÉDICAS SE MANIFESTAM SOBRE PRONUNCIAMENTO DE BOLSONARO. Gaúcha ZH, 2020. Disponível em: <https://gauchazh.clicrbs.com.br/coronavirusservico/noticia/2020/03/sociedade-brasileira-de-infectologia-eoutras-entidades-medicas-se-manifestam-sobre-pronunciamentode-bolsonaro-ck87d7hgj01gp01rzaqgikztj.html>. Acesso em 6 mai. 2020.

VARGAS, Mateus; PORTO, Gustavo. Após ato, Bolsonaro vê "histeria" em combate a Coronavírus e desafia Maia e Alcolumbre. Estadão, 2020. Disponível em: $<$ https://politica.estadao. com.br/noticias/geral,apos-ato-pro-governo-bolsonaro-desafia-maiae-alcolumbre-a-testarem-popularidade-nas-ruas, 70003234266>. Acesso e 5 mai. 2020.

VASCONCELOS, Renato. Coronavírus: relembro o que Bolsonaro já falou sobre a pandemia. Estadão, 2020. Disponível em: $<$ https:// politica.estadao.com.br/noticias/geral,coronavirus-o-que-bolsonaroja-falou-ate-agora-sobre-a-pandemia,70003234776>. Acesso em 5 mai. 2020.

WARDLE, Claire, DERAKHSHAN, Hossein. Report: Information Disorder: Toward an interdisciplinary framework for research and 

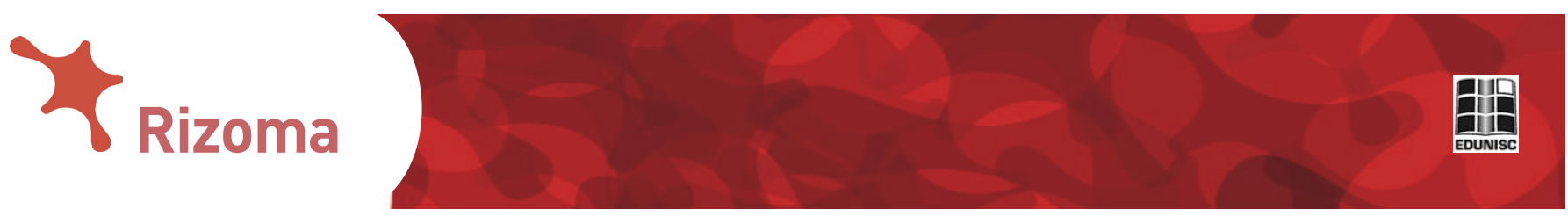

policy making. Conselho Europeu, Estrasburgo, 2017. Disponível em: https://rm.coe.int/information-disorder-toward-an-interdisciplinaryframework-for-researc/168076277c. Acesso em: 27 abr. 2020. 